\title{
Vertical Collectivism and Public Sector Corruption in South Asia: Fuzzy-set Qualitative Comparative Analysis
}

\author{
Jinwon Han \\ Ph.D. Student, Department of Indian and ASEAN Studies, \\ Graduate School of International and Area Studies, \\ Hankuk University of Foreign Studies, \\ Seoul, Republic of Korea
}

DOI: https://doi.org/10.36941/ajis-2020-0074

\section{Abstract}

Using fuzzy-set qualitative comparative analysis (fsQCA), this article intended to discover the combinations(s) of the vertical-collectivism dimensions inducing the high level of public sector corruption in South Asian countries. The analysis showed that the three combinations are instrumental in the high extent of public sector corruption in South Asian region: (a) the relatively low magnitude of power distance OR (b) the relatively low magnitude of masculinity AND the relatively high magnitude of uncertainty avoidance $O R$ (c) the relatively low magnitude of individualism AND the relatively high magnitude of uncertainty avoidance. The startling result is that the relatively low level of power distance was revealed as one of the core causal conditions affecting the high level of public sector corruption in South Asian region. On this notable result, this article argued that it resulted from the region's circumstances where the necessary resources and means to provide the less powerful members with an opportunity for upward social mobility is hardly achieved. In light of the finding, this article suggested that policy makers in South Asian countries should prioritize the improvement in regional situation which gives no other options to people, but corruption.

Keywords: Public Sector Corruption, Vertical-Collectivism, South Asia, Fuzzy-set Qualitative Comparative Analysis (fsQCA), Upward Social Mobility

\section{Introduction}

Public sector corruption is a serious malady afflicting South Asian region ${ }^{1}$. This ongoing trend is prevailing to such an extent that the region was ranked most corrupt region in the world (NDTV, 2014). As public sector corruption impacts almost all aspects of South Asian region adversely, it has come to fore as an entire regional issue. Therefore, it is important to explore the influencing factor(s) affecting the high level of public sector corruption in South Asian region.

Although there are several ways of investigating factors affecting corruption, those are broadly classified into three paradigms: individualistic approach, institutional approach, and socio-cultural approach (Kim \& Yoon, 1994). First, the individualistic approach to corruption holds that since corruption is fundamentally enacted by human beings, it is caused by individual attributions such as 
one's character, personality, or greed, etc. On the other hand, the institutional approach to corruption is grounded in the argument stating that corruption, as a social phenomenon, stems from institutional and administrative flaws such as administrative opacity, etc. Last but not least, the socio-cultural approach is the paradigm that suggests corruption is influenced by inherent sociocultural values, beliefs, and customs, etc. in each environment. ${ }^{2}$

Though the two former approaches, individualistic and institutional approach, have made important contributions to the understanding of corruption, each approach has limitations in applying to the context of South Asian region. First, individualistic approach has kept their argument within the realm of historical descriptive analysis in a single case and rhetorical explanations. Therefore, the individualistic approach is difficult to apply for comparative and empirical study in the context of South Asian region. And, with institutional approach, we cannot account for why the degree of (public sector) corruption shows a difference in South Asian countries, where institutions aimed at tackling corruption are well-equipped with ${ }^{3}$.

By contrast, a socio-cultural approach to corruption is appropriate for comparative study and can possibly explain why countries display a difference in terms of the level of public sector corruption in South Asian setting in which states are sharing a similar institutional milieu. This article, therefore, adopts a socio-cultural approach to corruption among the three approaches.

Most literatures adopting socio-cultural approach to corruption have examined the impact of various socio-cultural variables on the degree of corruption such as national culture (Husted, 1999), religion (Shadabi, 2013), and nepotism (Cho \& Lee, 2006) etc. However, the studies have little focused on (public sector) corruption in the context of South Asian region, and the important issue involving the complex causality that characterizes the anatomy of corruption itself.

Corruption, as many scholars have argued, is a complex and multifactorial phenomenon (Ogundiya, 2009). Thus, it can be argued that corruption is affected by multiple socio-cultural factors, not by a single factor. Moreover, the socio-cultural factors are intrinsically interdependent in the way that they affect each other. Therefore, it can be anticipated that the level of corruption will be impacted by several different combination(s) of multiple socio-cultural factors, which has been neglected in previous studies.

It is generally understood that voluminous socio-cultural factors influence on the high level of public sector corruption in South Asian region. However, Khatri, Tsang, \& Begley (2006) and Khatri,

2. Since individuals can be recognized as a construct of society and culture, one may argue that individualistic and socio-cultural perspectives are sharing similar conceptual ground. The two perspectives, however, show a clear distinction in their level and unit of analysis. From the individualistic point of view, corruption shall be committed by specific kinds of people who have corruption-inducing personality or habit, regardless of where the ones fall into society or culture. Therefore, what is being primarily analyzed in an individualistic study is an individual him/herself. From the viewpoint of the socio-cultural aspect, on the other hand, societal and cultural circumstances may predispose people to susceptible to corruption issues, whether individuals originally have integrity or not. Although the unit of analysis is sometimes overlapped between individual and socio-cultural environment, mostly sociocultural circumstances are analyzed in a socio-cultural study.

3. Every country in South Asian region has anti-corruption legislation. For instance, (i) Afghanistan (Law of Campaign against Bribery and Official Corruption and ratification of UN Convention against Corruption in 20o8); (ii) Bangladesh (the Code of Criminal Procedure, the Prevention of Corruption Act, the Penal Code, and the Money Laundering Prevention Act, and acceptance of UNCAC in 2007); (iii) Bhutan (the Anti-Corruption Act and ratification of UNCAC in 2016); (iv) India (the Indian Penal Code, the Prevention of Corruption Act including the new amendment act, and ratification of UNCAC in 2011); (v) Maldives (the Prevention and Prohibition of Corruption Act, the Anti-Corruption Commission Act, the Penal Code, the Prevention of Money Laundering and Terrorism Financing Act, and acceptance of UNCAC in 2007); (vi) Nepal (the Prevention of Corruption Act, the Good Governance Management and Operation Act, the Anti-Money Laundering Prevention Act including new amendments, and ratification of UNCAC in 2011); (vii) Pakistan (the Prevention of Corruption Act, the National Accountability Bureau Ordinance, and ratification of UNCAC in 2007); (viii) Sri Lanka (the Penal Code, the Bribery Act, the Prevention of Corruption Act, the Prevention of Money Laundering Act, and ratification of UNCAC in 2004). 
Khilji, \& Mujtaba's work (2013), in this regard, present a useful theoretical framework for a sociocultural explanation on the high level of public sector corruption in South Asian region.

The authors argued that corruption in the public sector is most prevalent in vertical-collectivist societies such as South Asian region (Khatri, Khilji, \& Mujtaba, 2013). That is because the customs, such as ubiquitous hierarchy, inherent status difference, and respect for authority, are uncritically accepted and reproduced in vertical-collectivist societies. And, together these attributions make people more susceptible to favouring in-group members, facilitating epidemic corruption issues in the public sector. However, the authors overlooked one crucial fact that vertical-collectivism is a multi-dimensional concept. Accordingly, it can be inferred that the level of corruption in the public realm is also influenced by the combination(s) of vertical-collectivism dimensions, not by vertical-collectivism as itself.

With this background, this article aims to explore the combination(s) of vertical-collectivism dimensions affecting the high level of public sector corruption in six South Asian countries ${ }^{4}$. More specifically, subdividing the concept of vertical-collectivism into four dimensions by exploiting Hofstede's typology, this article attempts to discover combination(s) of the four dimensions inducing the high level of public sector corruption.

In order to conduct such a combinatorial analysis, this article uses an analytic technique so-called fuzzy set qualitative comparative analysis (fsQCA). This methodology is useful to reveal 'a specific cause or combination of causal conditions constitutes one of several possible paths to an outcome' (Ragin, 2006, p. 292). The detailed information on the methodology is presented in the third chapter.

The remainder of this article is structured as follows: in the second chapter, this article discusses theoretical backgrounds for the conceptions of vertical-collectivism and public sector corruption, and causal relation between them. It, then, elucidates the conceptual link between vertical-collectivism and Hofstede's cultural dimensions to justify that Hofstede's conceptual model can reflect vertical-collectivism dimensions. Next, this article introduces fsQCA methodology and research methods including the data and the process of data calibration in the third chapter. And, it carries out empirical analysis by using fsQCA 3.0 software ${ }^{5}$ and interprets the results in the fourth chapter. Finally, this article concludes based on the major findings and describes the implications.

\section{Theoretical Backgrounds}

\section{$2.1 \quad$ Vertical Collectivism}

To understand vertical-collectivism, it is necessary to conceptualize the concepts, verticalness and collectivism respectively. Since 'verticalness is superimposed upon the more fundamental dimension of collectivism' (Bhagat, Keida, Harveston, \& Triandis, 2002, p. 209), this article first discusses on collectivism, and then on verticalness.

Collectivism, in contrast with individualism, refers to a socio-cultural value that emphasizes on cohesiveness among individuals and prioritization of the group over the self (Zhang, 2020). Collectivism and individualism, according to Triandis (1995), are distinguished by four attributes as follows.

a) The definition of the self: collectivists define themselves as components of an in-group; individualists, on the other hand, define the self as an autonomous entity. Namely, the definition of the self is interdependent in collectivism and independent in individualism

b) The priority of goals: in collectivist society, if personal and in-group goals are overlapped, people deem that the in-group goal should have priority over their personal goal; whereas people in individual society deem that their personal goal should have priority over their ingroup goal in identical circumstances.

4. Because of the lack of data, this article limits the spatial scope to six South Asian countries (Bangladesh, Bhutan, India, Nepal, Pakistan, and Sri Lanka).

5. It is available at www.socsci.uci.edu/ cragin/fsQCA/software.shtml (Accessed: December 14, 2019). 
c) The norms, obligations, and duties versus individual processes as a driving force of social behaviour: as a determinant of their social behaviour, collectivists give more weight to norms, obligations, and duties than to individual processes such as attitudes; individualists, however, give more weight to internal processes such as personal attitudes and needs than to norms, obligations, and duties.

d) Focus on the importance of relationships: among collectivists, even if the cost of the relationship exceeds the benefit, an emphasis on the relationship is still common; among individualists, when the cost of the relationship exceeds the benefit, that relationship often dropped.

In addition to describing the attributes of collectivism, Triandis $(1995 ; 1996)$ highlighted that it is important to define the collectivism and individualism constructs polythetically. Because, it should not be assumed that everyone in collectivist society has all the attributes of collectivism and that everyone in individualist society has all the characteristics of individualism. Accordingly, the collectivism and individualism have several varieties depends on how the constructs of the two concepts are mixed.

Among the different variations of collectivism and individualism, the two most important species are the vertical and horizontal ones (Triandis, 1996). Verticalness, in contrast with horizontalness, is associated with 'one's propensity to stand out' (Bhagat, Keida, Harveston, \& Triandis, 2002, p. 210). In vertical societies, therefore, it is often presumed that people are different from one another, considered the hierarchy system as a fait accompli, and underlined status differences as well as respect for authority (Khatri, Tsang, \& Begley, 2006). Accordingly, the concept of verticalness is closely intertwined with the hierarchical order system in society.

By contrast, horizontal societies lay emphasis upon the concept of equality, see people as similar to one another, and therefore endeavor to reduce the social status gap and authority distinctions. The two dimensions can be combined with the collectivism and individualism to produce different four socio-cultural patterns, vertical collectivism (henceforth VC), vertical individualism (VI), horizontal collectivism (HC), and horizontal individualism (HI). Since this article mainly deals with VC, it continues the discussion primarily on VC.

Altogether, VC can be conceptualized as a socio-cultural pattern in which individuals define the self as an element of a group but the group members are different from each other in terms of social status, therefore rigid social hierarchy system in society is widely accepted (Singelis, Triandis, Bhawuk, \& Gelfand, 1995).

\subsection{Public Sector Corruption}

The term of public sector corruption is compounded from two concepts, public sector and corruption. Therefore, it is also necessary to define each term first.

The public sector refers to the institutions that are controlled and primarily financed by public authority. The public sector, in this regard, is classified into two realms, the public corporation sector and the general government sector.

The public corporation sector refers to market institutions that are controlled and financed by public authority. The general government sector, on the other hand, is the non-market institutions that consist mainly of central, state, and local government units together with social security funds imposed and controlled by those units (Hammouya, 1999). In sum, the public corporation sector and general government sector are divided according to the two fields' marketability/non-marketability. This article limits the term public sector to the general government sector. Because, this article mainly focuses on corruption undertaken by public servants who should provide public services for all citizens at no cost.

In the case of the term corruption, even though it has come to the fore as a prominent and significant social phenomenon since the 1990s, there is a hardly authoritative definition of corruption until recently (Kim, 2017). It is because the conception of corruption, per se, can take the various 
shapes and forms depends on its usage and context. Nevertheless, many scholars have defined the term of corruption as 'the misuse of public power for private benefits' (Khan, 1996) to conduct a comparative study (Treisman, 2000; Gerring \& Thacker, 2004).

Since the aim of this article is to comparatively investigate the combination(s) of VC dimensions influencing the high magnitude of public sector corruption in South Asian region, this article adopts the definition of corruption mentioned above - i.e. the misuse of public power for private benefits.

To sum up, this article conceptualizes the term of public sector corruption as the misuse of public power for private benefits at the non-market institutions that are controlled and financed by public authority (general government sector).

\subsection{Vertical Collectivism and Public Sector Corruption}

The mechanism of corruption partially takes the shape of an exchange system between two parties, the demander and the supplier (Macrae, 1982). Given the structure of corruption, it can be argued that public sector corruption is also organized into the process of exchange between the demander (mostly public servants who supposed to provide public service to citizens at no cost) and the supplier (whoever supplies a bribe or kickbacks, etc. to public servants for their own interests). A collectivistic trait of vertical collectivism, in this context, stimulates both demander and supplier to be prone to corrupt practices.

From a demander standpoint, public servants (the demander of corruption) in vertical collectivistic society are apt to do corrupt practices, even when there is no expectation that they would receive something in return. Because in vertical collectivistic society, where in-group goals and relationships take precedence over individual goals and duties, public servants are more likely that 'they feel duty-bound to allocate rewards more generously to in-group than out-group members' (Khatri, Tsang, \& Begley, 2006, p. 65).

Similarly, the suppliers of corruption in vertical collectivistic society are also liable to be exposed to the lures of corruption. Since individuals in vertical collectivistic society see themselves as interdependent and as part of a larger society, suppliers may feel less individually responsible for their actions, and therefore less guilty about offering a corruption. Mazar \& Aggarwal (2011) also provided an evidence that the collectivistic attribute in society promotes a corrupt practice. Therefore, it can be claimed that the exchange between public servants and suppliers, namely, public sector corruption is more likely to emerge in the vertical collectivistic society due to its collectivistic attributes.

Furthermore, once such an induced corrupt pattern is established, it tends to perpetuate due to the embedded hierarchical order in the vertical collectivistic society. For instance, even if disgruntled members of the vertical collectivistic society endeavor to combat public sector corruption issues, deeprooted hierarchical custom makes them uncritically accept the established corrupt pattern. That is, public sector corruption will be more crystallized on account of embedded hierarchical order which is the vertical attribute in the vertical collectivistic society. Altogether, the collectivistic attribute of VC is likely to cause the high level of public sector corruption. Moreover, vertical characteristic in vertical collectivistic society tends to crystallize the established public sector corruption pattern.

Khatkhate (2008), in this regard, presented an empirical evidence on the causality between VC and public sector corruption. He argued that public servants in the Danish village (considered as an individualistic society) are not able to keep a close relationship with others, which ensures more impartial decision making in matters of public interest. Public officials in an Indian village (considered as a collectivist society), on the other hand, are more likely to engage with their in-group members (e.g. caste, religion, etc.), thereby creating a fertile ground for rampant public sector corruption in the shape of cronyism and pecuniary gains. Li, Triandis, \& Yu (2006, p. 201) also, pointed that 'the countries that are most corrupt, according to the Transparency International Corruption Perceptions Index, tend to have vertical collectivist cultures'.

Based on the conceptual discussion above, it can be expected that the high level of VC is causally related to the high degree of public sector corruption in societies. To carry out empirical and 
combinatorial analysis on the causal relationship between the level of VC and public sector corruption, it is necessary to operationalize them. In the case of the degree of VC in society, unfortunately, its measurement has not been easy (Singelis, Triandis, Bhawuk, \& Gelfand, 1995). This article, thus, uses Hofstede's culture dimension framework to subdivide VC into four dimensions, and therefore, to overcome the limitation in its measurement issue.

\subsection{Vertical Collectivism and Hofstede's Four Cultural Dimensions}

Hofstede's cultural dimension theory refers to a framework for cross-cultural research. His model focuses on discerning the differences in culture across countries by distinguishing the dimensions of national culture. The concept of cultural dimensions in his model represents an independent preference for one state of affairs over another that distinguish countries from each other (Hofstede Insights, 2019). Hofstede's original cultural dimension theory proposed four dimensions as follows: power distance (PD), individualism versus collectivism (IDV), masculinity versus femininity (MAS), and uncertainty avoidance (UA) (Hofstede Insights, 2019). In addition to the original four dimensions, Hofstede later added the fifth and sixth cultural dimensions, so-called long-term orientation versus short term normative orientation (LTO) and indulgence versus restraint (IVR) (Hofstede, Hofstede, \& Minkov, 2010).

This article deploys Hofstede's original four-dimension models to quantify the extent of VC dimensions in South Asian countries instead of using his recent six-dimensions models. The rationale behind adopting original four-dimensions models instead of the six-dimensions model in this article is that the accumulated data of latter dimensions lacks, since the two dimensions are relatively recently introduced. Thus, it does not seem feasible that the latter dimensions can be exploited as the robust dataset for comparative analysis.

Amidst the four dimensions, power distance (henceforth PD) dimension expresses the degree to which the less powerful members of a society accept and expect that power is distributed unequally (Hofstede Insights, 2019). In short, 'the basic issue involved here is how a society handles inequalities among people' (Hofstede Insights, 2019). It should be noted here that the PD dimension represents an inequality, but defined by less powerful members, not by more powerful members. Because how power is distributed is usually explained by the behavior of the more powerful members (Hofstede, Hofstede, \& Minkov, 2010).

Based on the PD dimension, Hofstede's dataset quantifies the extent of the PD dimension in each country into a score so-called Power Distance Index (henceforth PDI). People in societies exhibiting a large degree of PDI more accept a hierarchical order in which everybody has a place, and which needs no further justification (Hofstede Insights, 2019). In societies with low PDI, on the other hand, people more strive to equalize the distribution of power and demand justification for inequalities of power (Hofstede Insights, 2019).

Individualism-collectivism (henceforth IDV) dimension describes the relationship between the individual and collectivity that prevails in each society. Individualism 'pertains to societies in which the ties between individuals are loose' (Hofstede, Hofstede, \& Minkov, 2010, p. 92). Therefore, people will be more likely to take care of only themselves and their immediate families in individual societies. Collectivism, as an opposite pole, is linked to a society in which 'people from birth onward are integrated into strong, cohesive in-groups, which throughout people's lifetime continue to protect them in exchange for unquestioning loyalty' (Hofstede, Hofstede, \& Minkov, 2010, p. 92). Thus, individuals in collectivistic societies would have a tight bond with their in-group members.

Individual societies characterized by the high level of IDV score, therefore, will be less likely to have an interpersonal connection among people. And, people in the societies will have a propensity to show a little sharing of responsibility beyond family (Hofstede Insights, 2019). Collectivistic societies characterized as having a low IDV score, on the other hand, will be more likely to emphasize strong group harmony. People in the societies, therefore, will be expected to show fidelity and respect to in-group members (Hofstede Insights, 2019). 
Masculinity-femininity (henceforth MAS) dimension refers to how much a society sticks with values, that is, traditional male and female roles. This dimension does not indicate mere masculinity and femininity as an individual character but, as a societal attribute, focuses on 'distinct gender roles and material success as opposed to a concern with overlapped gender roles and quality of life' (Hofstede, Hofstede, \& Minkov, 2010, p. 140). Accordingly, members in masculine societies will be more likely to prefer achievement, heroism, assertiveness, and material rewards for success, thus the society would be more competitive (Hofstede Insights, 2019). People in feminine societies, on the other hand, will incline towards cooperation, modesty, caring for the weak and quality of life, and therefore the society at large is more consensus-oriented (Hofstede Insights, 2019).

In societies with high MAS scores, it is more observed strict gender roles of men and women. Men, therefore, would be more expected to be tough to be the provider, and to be assertive for obtaining material success (Hofstede Insights, 2019). Women, on the other hand, would be asked to be more moderate than men. In societies showing a low degree of MAS scores, the gender roles would be less likely to be stereotyped. Therefore, men would be allowed to be sensitive, and women also could work hard for professional success in the societies. And, since the societies would be more likely to concentrate on the quality of life, harmony and cooperation are preferred over conflict and competition (Hofstede, Hofstede, \& Minkov, 2010).

Uncertainty Avoidance (henceforth UA) dimension indicates the degree to which the members of a society feel uncomfortable with uncertainty and ambiguity (Hofstede Insights, 2019). This dimension relates to the anxiety that society members feel when in uncertain or unknown situations.

In order to operationalize the conception of the UA dimension, Uncertainty Avoidance Index (henceforth UAI) was designed. Countries exhibiting strong UAI maintain rigid codes of belief and behaviour and are intolerant of unorthodox behavior and ideas (Hofstede Insights, 2019). Weak UAI societies, by contrast, maintain a more relaxed attitude in which practice counts more than principles (Hofstede Insights, 2019).

This article argues that Hofstede's four cultural dimensions mentioned above can be used as a proxy representing VC dimensions. Regarding PD dimension, people in vertical collectivistic society readily submit to the authorities of the in-group and are willing to acknowledge social status inequality among the members of society. Given the fact that PD dimension primarily deals with the concepts of power and inequality and reflects the strength of social hierarchy, there is a strong relationship in the emphasis on hierarchy in the vertical pattern and PD dimension (Hofstede, Hofstede, \& Minkov, 2010). Therefore, it can be argued that PD dimension can reflect the attribute of vertical collectivistic society and that the higher the level of the PDI (the lower the level of the PDI), the more vertical collectivistic society (the less vertical collectivistic society).

In the case of IDV, it explicitly manifests a characteristic of VC. Because, 'a society's position on this dimension is reflected in whether people's self-image is defined in terms of 'I' or 'we" (Hofstede Insights, 2019). According to Hofstede, Hofstede, \& Minkov (2010, p. 91), 'people in collectivistic societies learn to think of themselves as part of 'we' group, a relationship that is not voluntary but is instead given by nature'. The 'we' group, therefore, is the major source of one's identity in a collectivistic society (Hofstede, Hofstede, \& Minkov, 2010).

Most members of individualistic societies, on the other hand, recognize themselves as 'I'. The 'I' refers to their identity and is distinct from other member's 'I's. Considering the extent of VC in society is also determined whether the member of society define the self as a part of a group, Hofstede's IDV dimension can be regarded as a proper proxy for capturing a feature of VC. Thus, a causal relationship can be established between the IDV and VC as follow: the lower the degree of the IDV (the higher the degree of the IDV), the more vertical collectivistic society (the less vertical collectivistic society).

It is generally believed that a high level of masculinity (low level of femininity) is somehow related to the high degree of VC in society. However, since the society's masculinity is associated with preference for a material success such as promotion at work, fame, and high income, it is rather defined as the construct of individualism (Moon, 2005). Because material success, considered 
important in masculinity society, is accomplished by personal assertiveness, ambition, and competition which are the features of individualism. Adversely, societal femininity placing a high value on establishing cooperation, modesty, and harmonization is associated with the attribute of VC (Lalwani \& Shavitt, 2012; Kurman \& Sriram, 2002). Accordingly, this article postulates, unlike the general perception, that the lower the level of the MAS (the higher the level of the MAS), the more vertical collectivistic society (the less vertical collectivistic society).

In vertical collectivistic societies, people's social behavior is grounded in shared norms, perceived duties, and obligations, rather than in personal desires as well as internal process (Singelis, Triandis, Bhawuk, \& Gelfand, 1995). Accordingly, members of vertical collectivistic societies may tend to prefer doing what norms require, conforming to group customs, and complying with strong traditions (Triandis, 1995). That is, people in vertical collectivistic societies will be likely to act on relatively firm and certain standards, rather than on relatively flexible and uncertain ones. Consequently, people will be more likely to prefer institutions with well-established norms, rules, policies, and procedures to avoid ambiguity. Based on the discussions above, it can be argued that the preference for strong and certain societal institutions in vertical collectivistic societies is associated with the high level of uncertainty avoidance dimension (Getz \& Volkema, 20o1). Taken together, it can be inferred that the higher the level of the UAI (the lower the level of the UAI), the more vertical collectivistic society (the less vertical collectivistic society).

On the basis of earlier discussions about the causal relation between the high level of VC and public sector corruption in the last section, this article finally assumes: when there are the higher the level of PDI, the lower the level of IDV, the lower the level of MAS, and the higher the level of UAI i.e. the higher the level of $\mathrm{VC}$-, the higher the degree of public sector corruption in South Asian countries. This article attempts to analyze this assumption by applying fsQCA methodology.

\section{Methodology}

The qualitative comparative analysis (henceforth QCA) methodology was introduced by Ragin, which can be applied to small- and intermediate-N case study. It aims to unravel multiple conjunctural causal relations to an outcome by applying set-theoretic methods to cross-case evidence. The term, multiple conjunctural causal relations, in this context, refers to the assumption that the most social phenomena result from several different combination(s) of multiple causal factors, rather than from a single factor. Here, it is important to note that 'not only the presence but also the absence of a certain factor is also assessed as influential for the outcome and therefore measured' (Sehring, KorhonenKurki, \& Brockhaus, 2013, p. 2) in this combination.

The fuzzy-set qualitative comparative analysis (henceforth fsQCA) was geared to extend QCA. Because, QCA has methodological limitation in terms of its designing for factors and outcomes that are only the simple presence (described as 1) and absent (described as o) dichotomies. This simple dichotomy brings a significant loss of information on cases. For instance, even though some countries are enjoying a full democracy (i.e. expressed as 1 in democracy set) or completely no democracy (i.e. expressed as o in democracy set), most countries in the real world are somewhere between full democracy and none-democracy set (between 1 and o). Therefore, it may be difficult to precisely specify the status of cases by using QCA approach (Ragin, 2006). In response to this limitation, Ragin extended QCA by permitting membership scores in the interval between o and 1 , which is the so-called fsQCA.

FsQCA is logically grounded on the set-theoretic approach, unlike methodologies based on a correlational approach such as regression analysis. In correlational methodologies, each input variable is regarded as independent and the one with the highest statistical significance is presented as the most influential determinant (Sehring, Korhonen-Kurki, \& Brockhaus, 2013). FsQCA, on the other hand, has 
an aim at identifying a joint causal system that treats each causal condition ${ }^{6}$ as interdependent and complementary. Therefore, in fsQCA approach, even if one condition's explanatory power is relatively weak, this is considered as the condition that 'might be necessary to trigger another condition, thereby contributing to the outcome' (Sehring, Korhonen-Kurki, \& Brockhaus, 2013, p. 2).

In fsQCA methodology, the solution formula ${ }^{7}$ describing causality is expressed by Logical AND, Logical OR and Negation, which are denoted by '*', '+', and ' $\sim$ ' respectively. Logical AND means a set intersection which is the compound set combined by two or more conditions. Thus, the solution formula ' $\mathrm{A} * \mathrm{~B}=\mathrm{Z}$ ' implies that, if $\mathrm{A}$ (causal condition 1) AND B (causal condition 2) exist, then $\mathrm{Z}$ (outcome) occurs. In short, $\mathrm{Z}$ occurs only when $\mathrm{A}$ and $\mathrm{B}$ both exist.

Logical $O R$, on the other hand, refers to the union of sets, which is the set of all listed conditions in the collection. The solution term ' $\mathrm{A}+\mathrm{B}=\mathrm{Z}$ ', therefore, refers to a statement that if $\mathrm{A} O R$ B exists, then $\mathrm{Z}$ occurs. In other words, the outcome $\mathrm{Z}$ occurs when a case has either $\mathrm{A}$ or $\mathrm{B}$.

Negation, initially, indicates the absence of the set characterized as having a score of o in QCA. However, since 'numerical values are not restricted to the binary values 1 and o but extend to values between 1 and o as well in fsQCA' (Ragin, Patros, Strand, \& Claude, 2017, p. 47), Negation in fsQCA mostly refers to the case with low membership score (i.e. close to o) of a specific set. Furthermore, membership score of a case in a negated set can also be calculated by simply taking one minus the membership score of the set (1-fuzzy set membership score). For instance, if a researcher has a case with a membership score of 0.8 in the set of democratic countries, the case has a score of 0.2 in the set of not democratic countries (Ragin, Patros, Strand, \& Claude, 2017).

FsQCA methodology has been recognized as an integrated one having the potential to remedy the shortcomings of both variable-oriented methodology (quantitative approach) and case-oriented methodology (qualitative approach) (Choi, 2009). The variable-oriented methodology has relative advantages in that it can establish generalized relationships between variables by conducting an empirical analysis to many cases. However, it has also methodological disadvantages in terms of lack of in-depth analysis and displaying a case's complexity. Case-oriented methodology, as opposed to a variable-oriented approach, has the merits of showing the complexity and unique attributes of cases through in-depth research but has some drawbacks in terms of theoretical generality, empirical analysis, and its limited number of cases.

In this context, fsQCA approach is expected to complement the innate limitations of the two conventional methodologies. Because, on the one hand, a researcher can identify multi-causal relationship between conditions and outcome by applying fsQCA, thereby unravelling case complexity which has been inevitably neglected in variable-oriented methodologies. A researcher, on the other hand, can also measure the cases' relative status through the process of fine-grained membership scoring and calibration in fsQCA. The processes enable the researcher to carry out an empirical analysis with more than a handful of cases, thereby allowing medium-range generalization and theorizing which cannot be done by case-oriented methodologies. Therefore, fsQCA has a methodological significance in the sense that it not only offers a middle path between a variable-oriented approach and case-oriented approach but also transcends many of the limitations of both (Ragin, 2008).

Given the fact that this article aims at discovering how VC dimensions are combined, and then affect the high level of public sector corruption in South Asia, fsQCA methodology is deemed

6. In fsQCA's logic, the term, (causal) condition should be used, instead of independent variable. Because the use of this vocabulary is not only more correct formally but also diminishes the risk of confusing the underlying logic of fsQCA with that of methodologies notionally based on correlational approach such as regression analysis technique (Schneider E Wagemann, 2010). This article, therefore, uses the term, (causal) condition, when it comes to a factor causing the social phenomenon in the context of $f$ sQCA approach.

7. The empirical results of $f$ sQCA also should be called solution formula or solution term, not equation, since it is necessary to display the fact that $f$ SQCA and correlational approach are based on different mathematical procedures and epistemologies (Schneider E Wagemann, 2010). 
adequate to meet the research purpose of this article.

\subsection{Data}

In this article, $\mathrm{VC}$ dimensions are selected as a causal condition influencing the high degree of public sector corruption in South Asian region based on the theoretical discussion in the second chapter. To facilitate an empirical analysis for a causality between VC and public sector corruption, it is required to operationalize the level of VC dimensions and public sector corruption by exploiting comparable indicator or index that represents each concept. In case of VC dimensions, PDI, IDV, MAS, and UAI indices ranging from 1 to 100 are selected based on the discussion in the second chapter.

These indexes, initially, were collected from a large database of employee value scores within International Business Machines Corporation (IBM) from 1967 to 1973. Since then, the dataset has been collected from various sources and the most recent one was introduced in Hofstede's 2010 edition of book, Cultures and Organizations: Software of the Mind, which listed the scores on the dimensions for 76 countries, partly based on replications and extensions of the IBM study on different international populations and by different scholars (Hofstede Insights, 2019). This dataset is regarded as somewhat old one, because the most recent one was gathered in 2010. However, given that socio-cultural pattern in the country hardly differs in short term, and the replications studies using the dataset show no loss of validity (Zainuddin, Yasin, Arif, \& Hamid, 2018), it is deemed a still valid dataset.

The outcome of this article is the degree of public sector corruption. Although many indicators or indexes represent the country's level of public sector corruption, Corruption Perceptions Index (henceforth CPI) which is annually published by Transparency International (henceforth TI) is utilized in this article. This index is a o to 100 points scale which is calculated for 180 countries around the world. A score of o is described as highly corrupt, a score of 100 is described as very transparent, and it is based on 13 sources that collect the assessment (perception) of experts and business executives on some specific corrupt behaviour in the public sector (i.e. bribery, diversion of public funds, use of public office for private gain, nepotism in the civil service and state capture) (TI, 2018).

There are two rationales behind selecting TI's CPI as the indicator representing the magnitude of public sector corruption in this article. First, how TI defined the public sector is rather indicates the general government sector, which is parallel with the objective of this article. TI defined public sector as 'the government and its decentralised units - including the police, military, public roads, and transit authorities, primary schools and healthcare system - that use public funds and provide services based on the motivation to improve citizens' lives rather than to make a profit' (italics added) (TI, 2018). Second, the CPI has been widely used as a reliable data in many studies concerning (public sector) corruption (Treisman, 2000; Gerring \& Thacker, 2004). Each score of South Asian countries is presented in Table 1.

Table 1. South Asia Countries' Scores of Four Indexes (PDI, IDV, MAS, and UAI) and CPI

\begin{tabular}{|c|c|c|}
\hline Indicator & Country & Score \\
\hline \multirow{6}{*}{$\begin{array}{l}\text { Corruption Perceptions Index } \\
\text { (CPI) }\end{array}$} & Bangladesh & 26 \\
\hline & Bhutan & 68 \\
\hline & India & 41 \\
\hline & Nepal & 34 \\
\hline & Pakistan & 32 \\
\hline & Sri Lanka & 38 \\
\hline \multirow{6}{*}{$\begin{array}{l}\text { Power Distance Index } \\
\text { (PDI) }\end{array}$} & Bangladesh & 80 \\
\hline & Bhutan & 94 \\
\hline & India & 77 \\
\hline & Nepal & 65 \\
\hline & Pakistan & 55 \\
\hline & Sri Lanka & 80 \\
\hline
\end{tabular}




\begin{tabular}{|c|c|c|}
\hline Indicator & Country & Score \\
\hline \multirow{6}{*}{$\begin{array}{l}\text { Individualism versus Collectivism } \\
\text { (IDV) }\end{array}$} & Bangladesh & 20 \\
\hline & Bhutan & 52 \\
\hline & India & 48 \\
\hline & Nepal & 30 \\
\hline & Pakistan & 14 \\
\hline & Sri Lanka & 35 \\
\hline \multirow{6}{*}{$\begin{array}{l}\text { Masculinity versus Femininity } \\
\text { (MAS) }\end{array}$} & Bangladesh & 55 \\
\hline & Bhutan & 32 \\
\hline & India & 56 \\
\hline & Nepal & 40 \\
\hline & Pakistan & 50 \\
\hline & Sri Lanka & 10 \\
\hline \multirow{6}{*}{$\begin{array}{l}\text { Uncertainty Avoidance Index } \\
\text { (UAI) }\end{array}$} & Bangladesh & 60 \\
\hline & Bhutan & 28 \\
\hline & India & 40 \\
\hline & Nepal & 40 \\
\hline & Pakistan & 70 \\
\hline & Sri Lanka & 45 \\
\hline
\end{tabular}

Source: Hofstede Insights and Transparency International (2019)

\subsection{Data Calibration}

The raw data used in fsQCA is mainly transformed into a fuzzy membership score in the interval from o to 1 . Here, a researcher undergoes the process of calibration in order to convert the raw data to the fuzzy membership score. Although the process of calibration is not essential for using fsQCA, according to Ragin (2008), uncalibrated data is inferior to calibrated one. Because, the uncalibrated raw data cannot indicate whether the case is in the particular set, but only can display a relative position of the case. For example, 'with an uncalibrated measure of democracy, it is possible to know that one country is more democratic than another but still not know if it is more a democracy or an autocracy' (Ragin, 2008, p. 72). Therefore, this article also follows the process of calibration by using the calibration function which is inherent in fsQCA 3.0 software. The rationale behind using the calibration function in the software instead of other methods ${ }^{8}$ is that it is a useful tool that prevents researcher's arbitrary choice that may be involved in the calibration process.

To use the calibration function in the software, a researcher must specify the values of an interval scale variable that correspond to three qualitative breakpoints that structure a fuzzy set: the threshold for full membership (FI, fully in the set), the threshold for full non-membership (FO, fully out of the set), and the cross-over point (neither more in the set nor more out of the set) (Ragin, 2008). The full membership score and the full non-membership score are cut-off scores that specify that cases are either fully or fully not belonging to a particular set. The cross-over point is a turning point that determines whether a case more or less belongs to the particular set. These three benchmarks should be deliberately selected based on external criteria using a researcher's theoretical and substantive knowledge (Ragin, 2008).

Before using the calibration function, however, since the range of values of raw data in this article varies widely, it is necessary to adjust values measured on a different scale to a notionally common scale. Accordingly, this article first rescales the scores' range to scale ranging from o to 1 by using the formula

8. There are many ways to calibrate the raw data other than using the calibration function. Because, calibration is fundamentally grounded on researcher's theoretical and substantive knowledge (Ragin, 20o8). For detailed explanation on calibration methods, see Ragin (2008, pp. 85-97). 
so-called Min-Max Feature scaling (equation 1) and then sets maximum, minimum, and median values ${ }^{9}$ of each score as breakpoints corresponding to FI, FO, and cross-over point respectively.

$$
\frac{x-x_{\min }}{x_{\max }-x_{\min }}
$$

Values including raw data, normalized score, and calibrated membership score of each case are described in Table 2.

Table 2. Each Score in South Asia Countries

\begin{tabular}{|c|c|c|c|c|}
\hline Indicator & Country & Raw Data Score & Normalized Score & Membership Score \\
\hline \multirow{6}{*}{$\begin{array}{l}\text { Corruption Perceptions } \\
\text { Index }(100-\mathrm{CPI})^{*}\end{array}$} & Bangladesh & $74(26)^{*}$ & 0.74 & 0.95 \\
\hline & Bhutan & $32(68)^{*}$ & 0.32 & 0.05 \\
\hline & India & $59(41)^{*}$ & 0.59 & 0.38 \\
\hline & Nepal & $66(34)^{*}$ & 0.66 & 0.65 \\
\hline & Pakistan & $68(32)^{*}$ & 0.68 & 0.77 \\
\hline & Sri Lanka & $62(38)^{*}$ & 0.62 & 0.45 \\
\hline \multirow{6}{*}{$\begin{array}{l}\text { Power Distance Index } \\
\text { (PDI) }\end{array}$} & Bangladesh & 80 & 0.79 & 0.57 \\
\hline & Bhutan & 94 & 0.93 & 0.95 \\
\hline & India & 77 & 0.76 & 0.45 \\
\hline & Nepal & 65 & 0.64 & 0.15 \\
\hline & Pakistan & 55 & 0.54 & 0.05 \\
\hline & Sri Lanka & 80 & 0.79 & 0.57 \\
\hline \multirow{6}{*}{$\begin{array}{l}\text { Individualism versus } \\
\text { Collectivism (IDV) }\end{array}$} & Bangladesh & 20 & 0.19 & 0.12 \\
\hline & Bhutan & 52 & 0.51 & 0.95 \\
\hline & India & 48 & 0.47 & 0.92 \\
\hline & Nepal & 30 & 0.29 & 0.40 \\
\hline & Pakistan & 14 & 0.13 & 0.05 \\
\hline & Sri Lanka & 35 & 0.34 & 0.59 \\
\hline \multirow{6}{*}{$\begin{array}{l}\text { Masculinity versus } \\
\text { Femininity (MAS) }\end{array}$} & Bangladesh & 55 & 0.54 & 0.94 \\
\hline & Bhutan & 32 & 0.31 & 0.25 \\
\hline & India & 56 & 0.55 & 0.95 \\
\hline & Nepal & 40 & 0.39 & 0.39 \\
\hline & Pakistan & 50 & 0.49 & 0.80 \\
\hline & Sri Lanka & 10 & 0.09 & 0.05 \\
\hline \multirow{6}{*}{$\begin{array}{l}\text { Uncertainty Avoidance } \\
\text { Index (UAI) }\end{array}$} & Bangladesh & 60 & 0.59 & 0.87 \\
\hline & Bhutan & 28 & 0.27 & 0.05 \\
\hline & India & 40 & 0.39 & 0.37 \\
\hline & Nepal & 40 & 0.39 & 0.37 \\
\hline & Pakistan & 70 & 0.69 & 0.95 \\
\hline & Sri Lanka & 45 & 0.44 & 0.57 \\
\hline
\end{tabular}

* The initial score given in the CPI is higher for low levels of perceived corruption. Therefore, it should be necessary to interpret the score in reversing way to display the high degree of public sector corruption. To prevent misunderstanding, the CPI score is converted to a value subtracted from 100 (100 - existing CPI score).

Note: Each normalized score is cut off from its two decimal points.

Source: Transparency International and Hofstede Insights (2019)

\section{Fuzzy-set Qualitative Comparative Analysis and Findings}

To use fsQCA, a three-stage analytic procedure should be conducted. The first step is to construct a

9. The basic advantage of the median value in calibrating, compared to the mean value, is that it is not skewed so much by a small proportion of extremely large or small values, and so it may give a better idea of a typical value. 
truth table from the fuzzy data, which includes specifying the given outcome for each combination and determining which combinations to include in the analysis (Ragin, Patros, Strand, \& Claude, 2017). The second step involves specifying the causal conditions and outcomes to minimize (Ragin, Patros, Strand, \& Claude, 2017). And the third step is to choose between specify analysis technique versus standard analysis technique. Thus, this article also proceeds analysis based on the above procedures.

\subsection{Truth Table Algorithm}

To conduct fsQCA analysis, it is necessary to reconstruct the fuzzy set data matrix as a truth table (Ragin, Patros, Strand, \& Claude, 2017). Initial truth table lists all the logically possible combinations of causal conditions for the outcome. Each row in a truth table lists all the possible $2^{k}$ combinations of potential causal conditions (where $\mathrm{k}$ is the number of causal conditions) (Ragin, 2008). Values in each row are described as 1 and o, which refer to a relatively the high level for the condition (when the fuzzy set memberships score is higher than the cross-over point) and low level for the condition (when the fuzzy set membership score is lower than the cross-over point) respectively. ${ }^{10}$

As a next step, it is necessary to minimize the initial truth table to leave only relevant combination(s) for the outcome. Here, a researcher should develop a rule for classifying some combinations as relevant and others as irrelevant, based on their frequency and consistency level (Ragin, 2008). The level of frequency is determined by establishing a frequency threshold based on the number of cases in each row. According to Ragin (2008, p. 143), 'when the total number of cases included in a study is relatively small, the frequency threshold should be 1 or 2 '.

Consistency, as a turning point that determines whether the combinations(s) is a subset of the outcome (set-theoretically significant or not), is determined by setting a consistency score. In general, consistency score should be as close to 1.0 (perfect consistency) as possible or at least above o.75. Because, it becomes difficult on maintaining that a subset relation exists with observed consistency score below 0.75 (Ragin, 2008). Since this article deals with relatively small-N cases (six cases), the frequency threshold is set as 1 and consistency score as o.8. Table 3 displays all the relevant combinations for the outcome after the minimizing procedure.

Table 3. The Minimized Truth Table

\begin{tabular}{|c|c|c|c|c|c|c|c|}
\hline \multicolumn{4}{|c|}{$\begin{array}{l}\text { Configurations of } \\
\text { Causal Conditions }\end{array}$} & \multirow{2}{*}{$\begin{array}{c}\text { Configurations of an } \\
\text { Outcome }\end{array}$} & \multirow{2}{*}{$\begin{array}{c}\text { Raw } \\
\text { Consistency* }^{*}\end{array}$} & \multirow{2}{*}{$\begin{array}{c}\text { PRI } \\
\text { Consistency** }^{*}\end{array}$} & \multirow{2}{*}{$\begin{array}{c}\text { SYM } \\
\text { Consistency }^{* * *}\end{array}$} \\
\hline PDI & IDV & MAS & UAI & & & & \\
\hline o & o & o & o & 1 & 1 & 1 & 1 \\
\hline 1 & o & 1 & 1 & 1 & 1 & 1 & 1 \\
\hline o & o & 1 & 1 & 1 & 0.983146 & 0.969072 & 1 \\
\hline 1 & 1 & o & 1 & 1 & 0.870968 & 0.076923 & 0.090909 \\
\hline o & 1 & 1 & o & 1 & 0.859504 & 0.392857 & 0.392857 \\
\hline \multicolumn{8}{|c|}{$\begin{array}{l}\text { * Meaning that the degree to which membership is a consistent subset of membership in the outcome } \\
\text { (Ragin, Patros, Strand, \& Claude, 2017). } \\
\text { ** Meaning that an alternative measure of consistency for fuzzy sets based on a quasi-proportional } \\
\text { reduction in error calculation (Ragin, Patros, Strand, \& Claude, 2017). } \\
\text { *** Meaning that an alternative measure of consistency for fuzzy sets based on the asymmetrical version } \\
\text { of PRI consistency (Ragin, Patros, Strand, \& Claude, 2017). }\end{array}$} \\
\hline
\end{tabular}

Source: Author

10. Originally, 1 and o refer to the presence and absence of each condition. In $f_{s} Q C A$, however, the relative position of each condition can be measured by assigning membership scores. Thus, 1 and o can be interpreted as the relatively the high degree for specified condition and relatively low degree for specified condition respectively. 


\subsection{Standard Analysis}

As the following procedure, a researcher must choose analytic technique options between specify analysis and standard analysis. The researcher can obtain only one solution through specify analysis technique, the most complex solution. By contrast, standard analysis technique automatically provides a researcher with the complex, intermediate, and parsimonious solutions. Since the standard analysis technique generates three solutions, it is recommended over specify analysis technique (Ragin, Patros, Strand, \& Claude, 2017). This article also carries out standard analysis instead of specify analysis based on the recommendation.

Among the three solutions, the complex solution presents a somewhat straightforward resulting solution that does not include any remainder combinations as potential counterfactual cases ${ }^{11}$. In effect, all the remainder combinations without strong instances or with very few strong instances are completely regarded as irrelevant in the complex solution (Ragin, 2008).

By contrast, the parsimonious solution incorporates the designation of all remainder combinations that yields a logically simpler solution, regardless of whether the counterfactual is easy or difficult ${ }^{12}$ (Ragin, 2008). Note that since the parsimonious solution covers all the remainder combinations, the formulas in that solution must be included in any representation of the outcome. Therefore, the terms included in the parsimonious solution are the decisive causal conditions that distinguish combinations of conditions that are consistent subsets of the outcome from those that are not' (Ragin, 2008, p. 204). Accordingly, the solution formulas in parsimonious solution are considered as the core causal conditions (prime implicants).

The intermediate solution is only derived from standard analysis technique. It is produced by counterfactual analysis based on researcher's substantive and theoretical assumption about causal conditions for the outcome (Ragin, 2008). More specifically, the intermediate solution can be obtained 'by removing individual causal conditions that are inconsistent with existing knowledge from combinations in the complex solution while maintaining the subset relation with the parsimonious solution' (Ragin, 2008, p. 172). Because the intermediate solution strikes a balance between complexity and parsimony, it is regarded as an optimal solution among the three solutions (Ragin, 2008). Since this article aims at discovering a combination(s) of VC dimensions influencing on the high level of public sector corruption in South Asian countries with an assumption discussed in the second chapter, only the intermediate solution is presented in Table $4 .{ }^{13}$

11. A counterfactual case is a substantively relevant combination of causal conditions that nevertheless does not exist empirically. The counterfactual analysis involves evaluating the outcome that such a case would exhibit, if, is existed (Ragin, 2008).

12. Easy counterfactuals assume that adding a redundant causal condition to a combination known to yield the outcome would still generate the outcome. Difficult counterfactuals, by contrast, try to remove a known causal condition from a combination displaying the outcome, on the assumption that this cause is redundant, and the reduced combination would still generate the outcome (Ragin E Sonnett, 2005).

13. Two other solutions are also presented in Appendix 1 and 2. 
Table 4. The Intermediate Solutions

\begin{tabular}{|c|c|c|c|c|c|}
\hline Configurations & $\begin{array}{c}\text { Raw } \\
\text { Coverage* }\end{array}$ & $\begin{array}{c}\text { Unique } \\
\text { Coverage }^{* *}\end{array}$ & Consistency $^{* * *}$ & $\begin{array}{c}\text { Solution } \\
\text { Coverage }^{* * * *}\end{array}$ & $\begin{array}{r}\text { Solv } \\
\text { Consist }\end{array}$ \\
\hline & 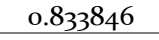 & & & \multirow{3}{*}{0.975385} & \multirow{3}{*}{$0.8255^{21}$} \\
\hline & & & & & \\
\hline$\sim$ IDV & 0.784615 & 0.13 & 0 & & \\
\hline \multirow{2}{*}{\multicolumn{6}{|c|}{$\begin{array}{l}\text { * Indicating the proportion of memberships in the outcome explained by each term of the solution (Ragin, } \\
\text { Patros, Strand, \& Claude, 2017). }\end{array}$}} \\
\hline & & & & & \\
\hline \multicolumn{6}{|c|}{$\begin{array}{l}\text { ** Indicating the proportion of memberships in the outcome explained solely by each solution term (Ragin, } \\
\text { Patros, Strand, \& Claude, 2017). }\end{array}$} \\
\hline \multicolumn{6}{|c|}{$\begin{array}{l}\text { *** Indicating the degree to which membership in the solution is a subset of membership in the outcome } \\
\text { (Ragin, Patros, Strand, \& Claude, 2017). }\end{array}$} \\
\hline \multicolumn{6}{|c|}{$\begin{array}{l}* * * \text { It measures the proportion of memberships in the outcome that is explained by the complete solution } \\
\text { (Ragin, Patros, Strand, \& Claude, 2017). }\end{array}$} \\
\hline \multicolumn{6}{|c|}{$\begin{array}{l}* * * * \text { It measures the degree to which membership in the solution is a subset of membership in the outcome } \\
\text { (Ragin, Patros, Strand, \& Claude, 2017). }\end{array}$} \\
\hline & & & & & \\
\hline
\end{tabular}

\section{Source: Author}

Based on the expectation that was developed earlier in the second chapter, the intermediate solution offered three causal combinations inducing the outcome: (a) the relatively low magnitude of power distance ( PDI) OR (b) the relatively low magnitude of masculinity (the relatively high magnitude of femininity) $A N D$ the relatively high magnitude of uncertainty avoidance ( MAS*UAI) OR (c) the relatively low magnitude of individualism (the relatively high magnitude of collectivism) AND the relatively high magnitude of uncertainty avoidance ( $\left.\sim \mathrm{IDV}^{*} \mathrm{UAI}\right)$. The three causal combinations explain approximately $97 \%$ of the outcome (o.975385). And, the combinations are consistent with the outcome (o.825521).

This result shows that, as expected, the three causal conditions are revealed as influencing factors on the high level of public sector corruption in South Asian region ( IDV, MAS, and UAI). However, the notable result is that not only the relatively low magnitude of PD condition ( PDI) is revealed as a causal condition affecting the outcome, but also is identified as one of the prime implicants (see Appendix 2). This result implies that the more people question inequality and demand appropriate justification for inequalities of power, the higher the level of public sector corruption occurs in South Asian region. On this startling result, this article contends that it stems from the situation in South Asian region, where the infrastructure for education or other means of social movement is poor.

According to Hofstede, Hofstede, \& Minkov (2010), societies with low PDI score are characterized by greater social mobility. It implies that less powerful members of societies with low PDI score will be more likely to strive for an upward social mobility. In the context of South Asian region, however, people are less likely to have opportunities for a movement from one social level to a higher one. Because, most countries in South Asian region have long faced a low level of social mobility. This trend can be identified by the research showing that South Asia stands out as region with some of the lowest levels of mobility (World Economic Forum, 2018). In this context, corruption has become the most effective institutionalized means of social movement in South Asian region, where the ways for social movement of members within or between social strata are sparse. This regional context gives no social options to people in South Asian region, but corruption.

\section{Conclusion}

South Asian region has long been suffered from public sector corruption issue. However, there has 
been very little research on socio-cultural factors inducing such a high level of public sector corruption in the region. The purpose of this article was, therefore, to explore causal combinations of socio-cultural factors affecting the high level of public sector corruption in South Asian region. To analyze, this article empirically examined the relationship between the level of VC dimensions and public sector corruption in South Asian region by using fsQCA approach. The analysis showed that three combinations of causal conditions are instrumental in the high level of public sector corruption in South Asian countries: (a) the relatively low magnitude of power distance ( PDI) OR (b) the relatively low magnitude of masculinity (the relatively high magnitude of femininity) $A N D$ the relatively high magnitude of uncertainty avoidance ( MAS*UAI) $O R$ (c) the relatively low magnitude of individualism (the relatively high magnitude of collectivism) AND the relatively high magnitude of uncertainty avoidance ( $\sim \mathrm{IDV} * \mathrm{UAI})$.

What's the interesting result is that the relatively low level of PD condition was revealed as a core causal condition inducing the high degree of public sector corruption in South Asian region $(\sim \mathrm{PDI})$. On this contrasting result, this article argued that it has been derived from the region's circumstances in which the necessary resources or social structure to provide the less powerful members in South Asian region with opportunities for their upward social mobility is hardly achieved. Although this regional circumstance has been certainly affected by many socio-cultural factors, it seems that deep-rooted social class systems, such as caste system etc., have played a decisive role in creating this situation. However, further research is needed on this expectation. Consequently, this regional condition has left uninfluential people in South Asian countries no choice but to utilize corruption as a means of their upward social mobility.

In light of the finding, this article suggests that it is certainly important for policy makers in South Asian region to build an environment which can present various opportunities for moving up the socio-economic ladder to less powerful members. Because, the regional circumstance with a low social mobility inevitably offers an environment in which people in South Asian region would be forced to select corruption for their social movement to a higher status. This can possibly explain why most countries in South Asian region have long faced pervasive corruption issues in the public sector, despite of their well-organized institutions for preventing one's corrupt activity.

This article contributes to the field of South Asian studies by examining the relationship between the level of VC dimensions and public sector corruption, which has been rarely focusing on. More specifically, it presents a combinatorial explanation for how VC dimensions combined each other and affected the high level of public sector corruption in South Asian region.

\section{References}

Bhagat, R. S., Keida B. L., Harveston, P. D., \& Triandis H C. (2002). Cultural Variations in The Cross-Border Transfer of Organizational Knowledge: An Integrative Framework. The Academy of Management Review, 27(2), 204-221.

Cho, E-K., \& C-J., Lee. (2006). Analyzing the Corruption-inducing Elements of Nepotism Culture among Countries. Korean Public Administration Review, 40(4), 491-509.

Choi, Y. J. (2009). Application of Fuzzy-set Theory in Social Sciences. Journal of Government Studies, 15(3), 307-336.

Gerring, J., \& Thacker, S. C. (2004). Political Institutions and Corruption: The Role of Unitarism and Parliamentarism. British Journal of Political Science, 34(2), 295-330.

Getz, K. A., \& Volkema, R. J. (2001). Culture, Perceived Corruption, and Economics: A Model of Predictors and Outcomes. Business \& Society, 40(1), 7-30.

Hammouya, M. (1999). Statistics on Public Sector Employment: Methodology, Structures and Trends. Geneva: International Labour Office.

Hofstede, G., Hofstede, G. J., \& Minkov, M. (2010). Cultures and Organizations: Software of The Mind. (3rd ed.). New York: McGraw Hill.

Hofstede Insights, (2019), National Culture. [Online] Available: https://hi.hofstede-insights.com/national-culture (March 11, 2010).

Husted, B. W. (1999). Wealth, Culture, and Corruption. Journal of International Business Studies, 30(3), 339 -359.

Khan, M. H. (1996). A Typology of Corrupt Transactions in Developing Countries. IDS Bulletin, 27(2), 12-21. 
Khatkhate, D. (2008). Ruminations of A Gadfly: Persons, Places, Perceptions. New Delhi: Academic Foundation.

Khatri, N., Tsang, E. W. K., \& Begley, T. M. (2006). Cronyism: A Cross-cultural Analysis. Journal of International Business Studies, 37(1), 61-75.

Khatri, N., Khilji, S. E., \& Mujtaba, B. (2013). Anatomy of Corruption in South Asia. In Khilji, S. E., \& Rowley, C. (Eds.), Globalization, Change and Learning in South Asia (pp. 63-82). Oxford: Chandos Publishing.

Kim, H-D., \& T-B., Yoon. (1994). Bureaucratic Corruption and its Control. Seoul: Beobmunsa.

Kim, J. Y. (2017). A Study on The Definition of Corruption Concept. Journal of Korean Corruption Studies Review, $22(4), 81-100$.

Kurman, J., \& Sriram, N. (2002). Interrelationships among Vertical and Horizontal Collectivism, Modesty, and Self-Enhancement. Journal of Cross-Cultural Psychology, 33(1), 71-86.

Lalwani A. K., \& Shavitt, S. (2012). The Relation between Gender and Cultural Orientation and Its Implications for Advertising. In Shintaro, O. (Ed.), Handbook of Research on International Advertising (pp. 455-470). Northhampton: Edward Elgar.

Li, S., Triandis H. C., \& Yu, Y. (2006). Cultural Orientation and Corruption. Ethics E Behavior, 16(3), $199-215$.

Macrae, J. (1982). Underdevelopment and The Economics of Corruption: A Game Theory Approach. World Development, 10(8), 677-687.

Mazar, N., \& Aggarwal P. (2011). Greasing the Palm: Can Collectivism Promote Bribery? Psychological Science, $22(7), 843-848$.

Moon, H-C. (2005). The Relationship between East Asian Cultures and Competitiveness: A Comparative Study of Korea, Japan, and China. Journal of International Area Studies, 14(1), 1-19.

NDTV, (2014), South Asia is World's Most Corrupt Region: Transparency International. [Online] Available: https://www.ndtv.com/india-news/south-asia-is-worlds-most-corrupt-region-transparency-international563198 (March 10, 2020).

Ogundiya, I. S. (2009). Political Corruption in Nigeria: Theoretical Perspectives and Some Explanations. The Anthropologist, 11(4), 281-292.

Ragin, C. C., \& Sonnett J. (2005). Between Complexity and Parsimony: Limited Diversity, Counterfactual Cases, and Comparative Analysis. In Kropp, S., \& Minkenberg, M. (Eds.), Vergleichen in der Politikwissenschaft (pp. 180-197). Wiesbaden: VS Verlag für Sozialwissenschaften.

Ragin, C. C. (2006). Set Relations in Social Research: Evaluating Their Consistency and Coverage. Political Analysis, 14(3), 291-310.

Ragin, C. C. (2008). Redesigning Social Inquiry: Fuzzy Sets and Beyond. Chicago: University of Chicago Press.

Ragin, C. C., T. Patros, Strand, S. I., \& Claude R. (2017). USER'S GUIDE TO Fuzzy-Set / Qualitative Comparative Analysis. [Online] Available: http://www.socsci.uci.edu/ cragin/fsQCA/software.shtml (January 4, 2020).

Schneider, C. Q., \& Wagemann, C. (2010). Standards of Good Practice in Qualitative Comparative Analysis (QCA) and Fuzzy-sets. Comparative Sociology, 9, 1-22.

Sehring, J., Korhonen-Kurki, K., \& Brockhaus, M. (2013). Qualitative Comparative Analysis (QCA): An Application to Compare National REDD+ Policy Processes. Indonesia: CIFOR.

Shadabi, L. (2013). The Impact of Religion on Corruption. The Journal of Business Inquiry, 12(1), 102-117.

Singelis, T. M., Triandis, H. C., Bhawuk, D. P. S., \& Gelfand, M. J. (1995). Horizontal and Vertical Dimensions of Individualism and Collectivism: A theoretical and Measurement Refinement. Cross-Cultural Research, 29(3), 240-275.

TI (Transparency International). (2018). Corruption Perceptions Index 2018. [Online] Available: https://www.transparency.org/cpizo18 (March 13, 2020).

Treisman, D. (200o). The Causes of Corruption: A Cross-National Study. Journal of Public Economics, 76(3), 399457.

Triandis, H. C. (1995). Individualism E Collectivism. Colorado: Westview Press.

Triandis, H. C. (1996). The Psychological Measurement of Cultural Syndromes. American Psychologist, 51, 407-415.

World Economic Forum. (2018). This is How Your Parents Affect Your Social Mobility. [Online] Available: https://www.weforum.org/agenda/2018/o7/intergenerational-mobility-across-the-world-wheresocioeconomic-status-of-parents-matters-the-most-and-least (March 15, 2020).

Zainuddin, M., Yasin, I. M., Arif, I., \& Hamid, A. B. A. (2018). Alternative Cross-Cultural Theories: Why Still Hofstede? In Proceedings of International Conference on Economics, Management and Social Study (pp. 1-6).

Zhang, X. (2020). Chinese International Students and Citizenship: A Case Study in New Zealand. Singapore: Springer Nature Singapore Pte Ltd. 
Appendix 1. The Complex Solutions

\begin{tabular}{|c|c|c|c|c|c|}
\hline Configurations & $\begin{array}{c}\text { Raw } \\
\text { Coverage }\end{array}$ & $\begin{array}{c}\text { Unique } \\
\text { Coverage }\end{array}$ & Consistency & $\begin{array}{l}\text { Solution } \\
\text { Coverage }\end{array}$ & $\begin{array}{c}\text { Solution } \\
\text { Consistency }\end{array}$ \\
\hline$\sim \mathrm{IDV}^{\star} \mathrm{MAS}^{\star} \mathrm{UAI}$ & 0.673846 & 0.452308 & 0.986486 & \multirow{4}{*}{0.96} & \multirow{4}{*}{0.906977} \\
\hline$\sim \mathrm{PDI}^{*} \sim \mathrm{IDV}^{*} \sim \mathrm{MAS}^{*} \sim \mathrm{UAI}$ & 0.375385 & 0.0646154 & 1 & & \\
\hline$\sim \mathrm{PDI}^{*} \mathrm{IDV}^{*} \mathrm{MAS}^{*} \sim \mathrm{UAI}$ & 0.32 & 0.0923076 & 0.859504 & & \\
\hline $\mathrm{PDI}^{*} \mathrm{IDV}^{*} \sim \mathrm{MAS}{ }^{*} \mathrm{UAI}$ & 0.249231 & 0.0123077 & 0.870968 & & \\
\hline
\end{tabular}

Appendix 2. The Parsimonious Solutions

\begin{tabular}{|c|c|c|c|c|c|}
\hline Configurations & $\begin{array}{c}\text { Raw } \\
\text { Coverage }\end{array}$ & $\begin{array}{c}\text { Unique } \\
\text { Coverage }\end{array}$ & Consistency & $\begin{array}{l}\text { Solution } \\
\text { Coverage }\end{array}$ & $\begin{array}{c}\text { Solution } \\
\text { Consistency }\end{array}$ \\
\hline$\sim$ PDI & 0.833846 & 0.0892308 & 0.831288 & \multirow[b]{2}{*}{0.975385} & \multirow[b]{2}{*}{$0.8255^{21}$} \\
\hline UAI & 0.886154 & 0.141539 & 0.90566 & & \\
\hline
\end{tabular}

